\title{
Repeat Photocopying of Journal Articles
}

When viewed in the perspective of total copying, repeated photocopying of articles from journals published in the United States does not appear to be of sufficient volume to warrant special attention from library administration. A study of 8,023 photocopies produced by photoduplication services of three different research libraries reveals that only 178 (2.2 per cent) represented two or more repeat copies. No article was copied more than four times during the period surveyed.

$\mathrm{L}$ LIBRARY-OPERATED photoduplication services are an important means of disseminating information. Some libraries have used this means for many years to save their patrons from copying information by hand. Also, libraries have enabled distant patrons and other libraries to use their collections by providing photocopies through mail service. These photoduplication services follow the practice of filling individual requests for single copies as and when requested. Libraries place restrictions on the types of material which can be photocopied. Requests may remain unfilled for any one or more of the following reasons: journal issues are too tightly bound for photocopying, not yet received, on loan, not in the collection, in a deteriorated condition, at the bindery, missing, temporarily missing, not identified, in processing; or the requester fails to use proper request form, wants multiple copies, gives an incomplete citation, fails to include return address; or because of copyright restrictions, length of article, etc.

Dr. Clarke is Deputy Chief, Technical Services Division, National Library of Medicine. Mrs. Clarke is former Chief Medical Librarian, Hospital del Nino, Lima, Peru.
In operating a photoduplication service, the question of whether the same material is requested and photocopied more than once inevitably arises. The present paper reports on a survey of repeat photocopying of articles from journal titles published in the United States, as performed at three research libraries in recent years.

\section{METHOD}

The survey was conducted by examining records of three major photoduplication services located in large research libraries in the United States. The director of one of these requested anonymity for his library, thus all three must remain anonymous. Library A is a large research library located in a metropolis on the east coast. Library B is a research library famous for its holdings in science and technology. Library $\mathrm{C}$ serves a great midwestern university. All three photoduplication services receive requests from around the world.

All records for two peak months of photocopy activity, each one in different years, were examined at Library A. At Library B, the sample consisted of all requests filled in one year for randomly selected patrons and covered approxi- 
mately 11 per cent of the year's total. A complete year of records was examined at Library C. These three types of samples were combined to give a rounded approach for the examination.

\section{Findings}

A total of 8,023 photocopies of articles was produced from the 1,318 different journal titles published in the United States. This represents a mean of 6.1 photocopies produced per journal title. The 8,023 photocopies actually represented 7,845 different articles copied, because 178 photocopies were repeats of articles which had already been copied once during the survey. This represents a mean of 5.9 articles copied per journal title. Only by noting the overlap in journal titles copied in common by the three libraries were the two means this high, for if overlap were not taken into account, the number of journal titles would be higher. This would then reduce the means. Repeat copies of the same articles amounted to 2.2 per cent of the total number (178 repeat copies from 8,023 photocopies produced). Clearly, repeat photocopying of the same articles from journal titles published in the United States does occur, and it occurs within the time periods of the samples examined. The 2.2 per cent repeat copying is not an impressive amount, and it is less so when one considers that it required totaling the copying from samples taken at the three libraries to achieve it. Further, the above means of 5.9 and 6.1 approximate each other, so that the mean number of articles photocopied per journal title approaches the mean number of photocopies produced per journal title, all for journal titles published in the United States.

Note that repeat copying would be greater than reported here, since patrons at times do request more than one copy of the same article at the same time, but the photoduplication services in each instance furnished only one copy, auto- matically cancelling requests for extra copies.

From the 165 different articles copied repeatedly, 154 (93.3 per cent) were copied twice, nine were copied three times (5.4 per cent), and two were copied four times (1.3 per cent). Four was the highest frequency of repeat copies found, even combining the copying from the three libraries. Those articles copied repeatedly appeared in 130 different journal titles from among the 1,318 (9.9 per cent) journal titles photocopied. Only eleven journal titles (see Table 1) had articles copied more than two times; this represents 0.8 per cent of the 1,318 journal titles. Note that fortyfour of the 178 (24.7 per cent) repeat photocopies (not articles) were produced by a different photoduplication service than that which produced the "first" photocopy. In other words, if the other photoduplication service had not made the copy, there would have been no repeat copy of that article in this survey. There is a core list of articles in a core list of journal titles published in the United States which receive repeated photocopying. The size of this list of

TABLE 1.

TrtLe of Journals Published in the U.S. Having Articles Photocopied More Than Twice During the Period SURVEYED

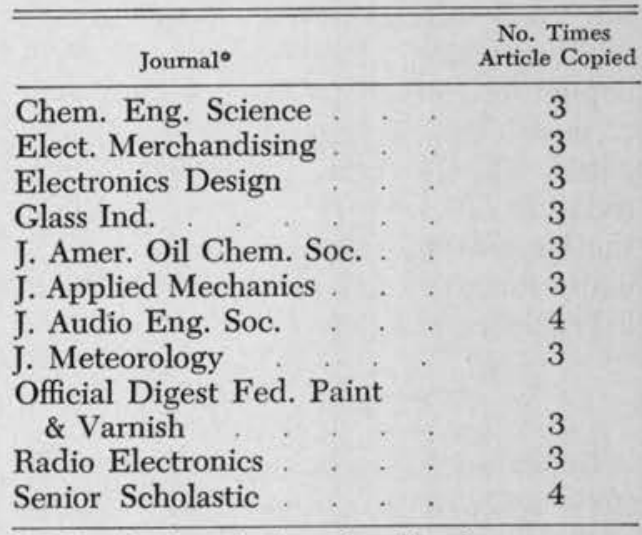

- Combined samples from three libraries. 
articles and journal titles decreases with an increase in repeated photocopying. These articles are copied at more than one photocopy service.

Since 134 ( 75.3 per cent) of the 178 repeat copies were produced in the same library that made the first copy during this survey, the same photoduplication service tends to recopy the same article within the same time period more than another photoduplication service tends to copy that same article during its time period examined. Note that the holdings of the different libraries and their policies and practices can influence repetition; for example, having material at the bindery, with the associated practices and schedules. All libraries do not hold the same journals in common, nor do all libraries offer photoduplication services, nor are all photoduplication services major ones, like those examined. All these factors tend to reduce the probability of repeated copying.

The age of the articles copied repeatedly is also of interest (see Table 2). The ages ranged from less than one year since publication to a maximum of sixtythree years at the time of copying. Their mean and median ages were 8.0 and 6.5 years respectively, with the mode occurring between one and two years of age when a total of twenty-eight articles were repeatedly copied. Not enough information is available to state whether the same articles in journals published in the United States are repeatedly copied down through the years, but it is a possibility which might be investigated. Clearly, there is repeated interest today in articles published in journals in the United States ranging back through many decades, as well as in those published in recent years.

\section{IMPLICATIONS}

Repeated photocopying of articles from journals published in the United States occurs in library photoduplication services. When viewed in the perspective of total copying, however, it does not appear to be of sufficient volume to warrant special attention by library administration. This seems even more nearly true in considering the volume of this repetition involving producing more than a second copy. Copyright would restrict production of multiple copies of articles thus protected, particularly the production of more than one copy at one time.

TABLE 2.

Age of Articles Copied More Than Once During the Period Surveyed, Which Appeared in Journal TtTles PUBLISHED IN THE U.S. ${ }^{\circ}$



\footnotetext{
- Combined samples from three libraries.
} 
Stockpiling of extra copies of noncopyrighted journal articles which have been photocopied once, or more likely more than once, might be studied. This examination should be from the viewpoint of considering storage costs for items which may never be asked for again, as well as production costs, and relating them to the present practice of photocopying only on demand, albeit if sometimes repeatedly.

\section{OPTIMUM SIZE . . .}

(Continued from page 357 )

areas. These libraries will depend upon the centers for their published output as an important device for aiding in the evaluation, digestion, and manageable assimilation of the literature for which they are responsible.

In such a development, all libraries could approach the problems of optimum size and of division of subject responsibility confidently and rationally.

There is considerable evidence that the great research libraries-government, university, and private-are already making tentative shifts to prepare themselves for their proper roles in the network of collections and services which must eventually evolve if we are to solve our problems. The national libraries of medicine, of agriculture, and other remarkable concentrations of subject strengths in various government departmental libraries are becoming accepted as true national resource centers, as indeed they have long tacitly been. There is much talk about the establishment of regional branches throughout the country. The Department of Agriculture has had socalled branches for many years, but not on the scale suggested here. The Library of Congress, which established a science and technology division only after World War II, and of course has tremendous resources and capabilities, is a central point in this shift and will spearhead many of the costly experiments and programs necessary to achieve it.

University libraries, for the first time, are separating their research functions in separate buildings, foreshadowing coming changes in function. At least one of them, Yale University, is separating its science research materials and will concentrate them in a new building.

The former Midwest Inter-Library Center has changed its name, and, from all indications, its future role in the research library picture in the nation. John Crerar and the Linda Hall libraries are becoming increasingly national resources, rather than limited local or regional library features. In Great Britain, the national lending library of science is a well established, working entity, and plans for a national science reference library are well along.

In conclusion, it might be said that "optimum size" techniques may need to be related to a situation in the scientific literature and in scientific libraries, which show every indication of radical and extensive changes ahead. These changes will come very quickly, for the pace of achievements in new knowledge and in new literature, which demands these changes, give us very little time. 